\title{
Evaluation of Parameters Affecting Measurement Quality of Dynamic Contour Tonometry
}

\author{
Baran Gencer, Vuslat Gürlü
}

Department of Ophthalmology, Faculty of Medicine, Trakya University, Edirne, Turkey

\begin{abstract}
Objective: To evaluate factors affecting measurement quality of dynamic contour tonometry (DCT).

Material and Methods: Three hundred patients took part in this prospective clinical study. For each patient, measurements for one eye were included in the study. Of the participants, 116 had ocular hypertension, 114 had glaucoma, and 70 had normal eyes. We used automatic refractokeratometry, ultrasonic pachimetry, Goldmann applanation tonometry, and DCT measurements to investigate the effects of age, corneal astigmatism, refractive error, central corneal thickness (CCT), intraocular pressures (IOP), and ocular pulse amplitude (OPA) on DCT measurement quality (Q). Logistic regression analysis was used for statistical analysis.

Results: For 159 patients, the DCT Q score was 1 (group 1). For the remaining 141 patients, the Q score was $2-3$ (group 2). The following values were determined for the two groups, respectively: mean age $58.9 \pm 9.9$ and $61.4 \pm 10.6$; mean corneal astigmatisms $-0.78 \pm 0.67$ and $-0.92 \pm 0.77$ diopter; mean spherical equivalents $0.33 \pm 1.87$ and $-0.01 \pm 2.02$ diopter; mean CCT $547.0 \pm 35.2$ and $549 \pm 38.7 \mu \mathrm{m}$. Measurements with DCT provided mean IOPs of $18.5 \pm 3.70$ and $21.27 \pm 6.19 \mathrm{~mm} \mathrm{Hg}$ and mean OPA $3.5 \pm 1.4$ and $3.2 \pm 1.2 \mathrm{~mm} \mathrm{Hg}$. By logistic regression analysis, we determined that the parameters affecting measurement quality were age, DCT measurement level, and OPA ( $p=0.015, p=0.000$, and $p=0.000$, respectively).
\end{abstract}

Conclusion: High IOP values, advanced age, and low OPA values can lead to decreased DCT measurement quality.

Key Words: Dynamic contour tonometry, ocular rigidity, Q score

Received: 27.10.2009 Accepted: 23.03.2010

\section{Introduction}

Goldmann applanation tonometry (GAT) is considered to be the gold standard among intraocular pressure (IOP) measurement methods. However, GAT measurements are affected by corneal thickness, corneal astigmatism, and corneal rigidity (1-6). This has led investigators to search for a tonometry that will measure IOP without being affected by central corneal thickness (CCT). Kanngiesser et al. (7) claim that dynamic contour tonometry (DCT) is not affected by corneal thickness, corneal curvature, or ocular rigidity. DCT is a slit lamp-mounted device for contact tonometry. A contour-matched pressure sensor tip is applied to the cornea, allowing transcorneal IOP to be measured directly (8). In published reports of manometric and clinical studies employing $D C T$, measurements correlate with GAT but are not affected by CCT (9-13).

Each time the dynamic contour tonometer computes and displays a diastolic IOP ocular pulse amplitude (OPA), the quality of the results is assessed and a "Q score" is computed and displayed. These scores are classified by the manufacturer as: Q1, optimum quality; Q2 and 3, acceptable; and Q4 and 5, not acceptable. A $Q$ score of 1-3 indicates that the result was com- puted from high-quality data and therefore can be assumed to be reliable. The manufacturer has stated that failure to centralize the DCT tip, corneal flatness, and insufficient or excessive tears may lead to incorrect measurements. Additionally, poor patient cooperation, short measurement times, and low OPA may also affect the $Q$ score (14). To our knowledge, however, no studies have been performed that investigate the effects of age, corneal astigmatism, spherical equivalents, CCT, GAT and DCT measurement level and OPA on the DCT $\mathrm{Q}$ score. Therefore, we decided to investigate parameters that affect the $\mathrm{Q}$ score of DCT in a prospective clinical study.

\section{Methods}

Three hundred consecutive patients were included in this prospective clinical study, which took place in the Glaucoma Unit, Ophthalmology Department, Trakya University Patients who did not provide sufficient measurement quality $(Q$ value of 4-5); those with corneal pathology; and those who had a history of ocular surgery, infection, or trauma were not included in the study.

Before enrollment, the procedures and aims of the study were explained to the patients, who signed an informed 
consent form. The study protocol and consent form were approved by the Institutional Review Board for clinical research.

We randomly evaluated one eye from each participant in the study. We then took measurements using the following techniques: automatic refractometry (Autoref/keratometer, ARK-700 A, Nidek Co, Tokyo, Japan), pachimetry, DCT, and GAT. CCT was performed following a biomicroscopic examination using an ultrasonic pachymeter (Ultrasonic Pachymeter SP-3000, Tomey Co, Tokyo, Japan). Following instillation of one drop of $0.05 \%$ proparacaine hdyrochloride to the eye, the pachimetry probe was placed perpendicular at $1.5 \mathrm{~mm}$ temporal of the corneal light reflection while the subject was looking at the fixation object. Three successive measurements were made, and the mean value of the three measurements was recorded as the CСT. The measurement was repeated for values with a deviation over $5 \mu \mathrm{m}$.

IOPs were first measured with GAT (Haag-Streit, Switzerland). Following staining of the tear film with a sodium florescein strip, the subject was asked to blink several times and the measurement was made under a cobalt blue filter. The measurement was repeated twice and the mean value was recorded. Care was taken to ensure that the patient's eye was sufficiently open and that no pressure was applied to the globe.

DCT (PASCAL tonometer, Swiss Microtechnology, Port, Switzerland) measurements were performed after GAT. First, the DCT control button was rotated approximately $10^{\circ}$ clockwise so that the device was ready to take measurements. After the patient had blinked his/her eyes several times, the DCT tip was brought close to the corneal apex, looking from the side. After the recording sign appeared on the second line of the LCD screen, the sensor tip of the biomicroscope was slowly brought closer until it made contact with the cornea. The sensor tip was centralized so as to ensure a dark and circular shape at the contact area. The measurement was completed by withdrawing the tonometry tip from the corneal surface after five beeps were heard. We recorded IOP, OPA, and measurement quality scores (Q) when they appeared on the LCD screen. All measurements were made by the same observer.

To compute the $\mathrm{Q}$ score, the data points collected were examined for characteristics such as noise level spikes (singularities) drift, and continuity. The amount of data available, i.e., the number of diastoles and systoles found, was also taken into consideration. The $\mathrm{Q}$ score obtained is a weighted composite of these components (14).

The cases were classified into two groups based on the $Q$ score. The patients with a measurement quality score of $Q=1$ (optimum quality) were placed in group 1 and subjects with $\mathrm{Q}=2-3$ (acceptable) were placed in group 2. In these groups, mean values of age, corneal astigmatism, spherical equivalents, CCT, GAT, DCT, and OPA were evaluated. Logistic regression analysis was performed to determine the factors that affect the quality of DCT measurements in all patients.

\section{Results}

The study participants, with a mean age of $60.0 \pm 10.3$ years (minimum 24 years, maximum 82 years), comprised 118 males (39.3\%) and 182 females (60.7\%). Of the eyes included in the study, 116 were ocular hypertensive (38.7\%), 114 were glaucomatous $(38.0 \%)$, and $70(23.3 \%)$ were normal. The mean corneal astigmatism of the patients was $-0.8 \pm 0.7$ diopter, with a mean spherical equivalent of $0.2 \pm 1.9$ diopter. The mean DCT of the patients was $19.8 \pm 5.2 \mathrm{mmHg}$, and the mean GAT was $18.9 \pm 6.3 \mathrm{~mm} \mathrm{Hg}$. The mean CCT was $548.4 \pm 36.8 \mu \mathrm{m}$, while the mean OPA was $3.4 \pm 1.3$.

Evaluation of the interrelation of these parameters with the correlation analysis revealed that there was a correlation between DCT measurements and GAT measurements and the $Q$ values $(r=0.875, p=0.000 ; r=0.293, p=0.000$ for DCT and GAT measurements, respectively). We determined that there was no correlation between the CCT and DCT values $(r=0.002, p=0.975)$.

For 159 eyes, the $\mathrm{Q}$ score was $\mathrm{Q}=1$ (optimum quality) (group 1). The quality score for the remaining 141 eyes was $\mathrm{Q}=2-3$ (acceptable) (group 2). The mean values of the parameters of the two groups are presented in Table 1.

Using logistic regression analysis, we determined that the parameters that affected the measurement quality were the IOP level, as measured by DCT $(p=0.000$, odds ratio=1.216); OPA $(p=0.000$, odds ratio $=0.657)$; and age $(p=0.015$, odds ratio=1.031).

\section{Discussion}

DCT is a novel, nonapplanation, contact digital tonometer. It was introduced in 2002 by Kanngiesser et al. (7) as an alternative to GAT. The tonometer tip touches the cornea and forces it into the shape that it is assumed it would take if the pressure was the same on both sides of the cornea. A pressure sensor incorporated into the tip measures the IOP precisely, with less influence on corneal properties when compared with other methods (8).

DCT has been compared with GAT, and their correlation with CCT has been evaluated (9-12). Pache et al. (9) found that mean DCT values were about $1 \mathrm{~mm} \mathrm{Hg}$ higher than GAT in 100 eyes with normal corneas of different thicknesses, and DCT did not show a significant correlation with CCT. Schneider and Grehn (10) reported that DCT measurements were not affected by CCT or corneal curvature in 100 patients who did not have glaucoma, and Kniestedt et al. (11) reached similar conclusions in patients with glaucoma. In patients with varying CCTs, Karahan et al. (12) and Eser et al. (13) found that DCT provided more precise results in thin corneas; however, it was

Table 1. Mean values of the parameters of two groups

\begin{tabular}{|lcc|}
\hline Parameters & $\begin{array}{c}\text { Group 1 } \\
(n=159)\end{array}$ & $\begin{array}{c}\text { Group 2 } \\
(n=141)\end{array}$ \\
\hline DCT $(\mathrm{mmHg})$ & $18.5 \pm 3.7$ & $21.3 \pm 6.2$ \\
GAT $(\mathrm{mmHg})$ & $17.5 \pm 4.3$ & $20.4 \pm 7.8$ \\
CCT $(\mu \mathrm{m})$ & $547.4 \pm 35.2$ & $549.4 \pm 38.7$ \\
OPA $(\mathrm{mmHg})$ & $3.5 \pm 1.4$ & $3.2 \pm 1.2$ \\
Age (years) & $58.8 \pm 10.0$ & $61.43 \pm 10.63$ \\
Corneal astigmatism (diopter) & $-0.78 \pm 0.67$ & $-0.91 \pm 0.76$ \\
Spherical equivalent (diopter) & $0.32 \pm 1.86$ & $0.00 \pm 2.01$ \\
\hline
\end{tabular}


not superior to GAT in patients with thick corneas. In agreement with the literature, we determined that DCT measurements were not correlated with CCT.

This study confirms that high IOP values, advanced age, and low OPA values lead to $\mathrm{Q}$ scores indicative of poor-quality measurements. The underlying mechanisms of how advanced age, increased IOP, and lower OPA values affect the $\mathrm{Q}$ score are unknown at this time. The effect of these parameters (which are correlated with one another) on DCT measurements is a topic that merits further research.

It is not surprising that contact tonometers (applanation or nonapplanation) are affected by biomechanical characteristics, because they measure pressure by direct contact with the cornea. Ocular rigidity is a parameter that defines the biomechanical characteristics of the eye tissues (sclera, cornea, and choroid). Recent studies have shown the relationship of age and IOP with ocular rigidity. Pallikaris et al. (15) evaluated ocular rigidity in 79 eyes from 79 patients and found that there was a positive correlation between the ocular rigidity coefficient and age. Another parameter that correlates with ocular rigidity is IOP. In studies employing direct manometric measurements, researchers showed that ocular rigidity increases with increasing IOP $(16,17)$. Like IOP, OPA is measured by DCT. OPA is the difference between the maximum (systolic) and minimum (diastolic) values of pulsatile IOP. While ocular rigidity increases with age, OPA decreases with advanced age (18).

In conclusion, varying DCT Q scores may be obtained even when all of the manufacturer's instructions are followed to the letter. High IOP, advanced age, and low OPA values can lead to poor-quality DCT measurements. DCT studies in which ocular rigidity is taken into account are required to determine the full effect of these parameters, which all relate to ocular rigidity, on DCT measurements.

\section{Conflict of Interest}

No conflict of interest was declared by the authors.

\section{References}

1. Whitacre MM, Stein R. Sources of error with use of Goldmanntype tonometers. Surv Ophthalmol 1993;38:1-30. [CrossRef]

2. Bhan A, Browning AC, Shah S, Hamilton R, Dave D, Dua HS. Effect of corneal thickness on intraocular pressure measurements with the pneumotonometer, Goldmann applanation tonometer and Tono-Pen. Invest Ophthalmol Vis Sci 2002;43:1389-92.
3. Li Q, Li M, Fan Z, Wang N. The influence of central corneal thickness and corneal curvature and axial length on the measurement of intraocular pressure. Yan Ke Xue Bao 2002;18:176-80.

4. Brandt JD, Beiser JA, Kass MA, Gordon MO. Central corneal thickness in the Ocular Hypertension Treatment Study (OHTS). Ophthalmology 2001;108:1779-88. [CrossRef]

5. Johnson M, Kass MA, Moses RA, Grodzki WJ. Increased corneal thickness simulating elevated intraocular pressure. Arch Ophthalmol 1978;96:664- 5 .

6. Bron AM, Creuzot-Garcher C, Goudeau-Boutillon S, d'Athis P. Falsely elevated intraocular pressure due to increased central corneal thickness. Graefes Arch Clin Exp Ophthalmol 1999;237:220-4. [CrossRef]

7. Kanngiester HE, Nee M, Kniestedt $\mathrm{C}$, et al. Simulation of dynamic contour tonometry compared to in-vitro study revealing minimal influence of corneal radius and astigmatism. The theoretical foundations of dynamic contour tonometry. Invest Ophthalmol Vis Sci 2003;44:2641.

8. Punjabi OS, Kniestedt C, Stamper RL, Lin SC. Dynamic contour tonometry: principle and use. Clin Experiment Ophthalmol 2006;34:837-40. [CrossRef]

9. Pache $\mathrm{M}$, Wilmsmeyer $\mathrm{S}$, Lautebach S, Funk J. Dynamic contour tonometry versus Goldmann applanation tonometry: a comparative study. Graefes Arch Clin Exp Ophthalmol 2005;243:763-7. [CrossRef]

10. Schneider E, Grehn F. Intraocular pressure measurement-Comparison of dynamic contour tonometry and Goldmann applanation tonometry. J Glaucoma 2006;15:2-6. [CrossRef]

11. Kniestedt C, Nee M, Stamper RL. Dynamic contour tonometry: a comparative study on human cadaver eyes. Arch Ophthalmol 2004;122:1287-93. [CrossRef]

12. Karahan E, Günenç Ü, Arıkan G, Ergin MH. Goldmann aplanasyon tonometresi ve paskal dinamik kontur tonometrenin karşılaştırılması ve merkezi kornea kalınlığının göz içi basıncı ölçümlerine etkisi. Glokom-Katarakt 2009;4:150-6.

13. Eser E, Başer EF, Seymenoğlu G. Dinamik kontur tonometre, nonkontakt tonometre, tonopen ve goldmann aplanasyon tonometresi ile göz içi basıncı ölçümlerinin santral kornea kalınlığı ile ilişkisi. Glokom- Katarakt 2008;3:107-12.

14. Pascal User Manual CDRom. Version 2.0, November 2004.p.51-2.

15. Pallikaris IG, Kymionis GD, Ginis HS, Kounis GA, Tsilimbaris MK. Ocular rigidity in living human eyes. Invest Ophthalmol Vis Sci 2005;46:409-14.

16. Ytteborg J. The effect of intraocular pressure on rigidity coefficient in the human eye. Acta Ophthalmol (Copenh) 1960;38:548-61. [CrossRef]

17. Eisenlohr JE, Langham ME, Maumenee AE. Manometric studies of the pressure-volume relationship in living and enucleated eyes of individual human subject. Br J Ophthalmol 1962;46:536-48. [CrossRef]

18. Geyer O, Silver DM, Mathalon N, Massey AD. Gender and age effects on pulsatile ocular blood flow. Ophthalmic Res 2003;35:247-50. [CrossRef] 